\title{
Utilization of Antenatal care Services in a selected Rural area in Bangladesh
}

\author{
N Begum ${ }^{1}$, M Rahman' ${ }^{2}$ M M Rahman ${ }^{3}$, S K Nayann ${ }^{4}$, S Z Zinia ${ }^{5}$, S Z Khan ${ }^{6}$
}

${ }^{1}$ Dr. Nasreen Begum MBBS, MPH

Assistant Professor

Dept. of Community Medicine

Northern International Medical College

2

${ }^{2}$ Dr. Mumtaz Rahman

MBBS, MPH

Assistant Professor

Dept. of Community Medicine

Northern International Medical College

3 Prof. Dr. Md. Mahbubar Rahman MBBS, MPH

Dept. of Community Medicine

Dhaka Central International Medical College

Dr. Shafia Khatun Nayan

MBBS, MPH

Lecturer

Dept. of Community Medicine

Northern International Medical College

5

Dr. Sumsun Nahar Zinia

MBBS, MPH

Lecturer

Dept. of Community Medicine

Northern International Medical College

${ }^{6}$ Dr. Sharmin Zaman Khan

MBBS

Lecturer

Dept. of Community Medicine

Northern International Medical College

\section{Correspondence}

Dr. Nasreen Begum

MBBS, MPH

Assistant Professor

Dept. of Community Medicine

Northern International Medical College

\section{Abstract}

Background : Antenatal care, the care that a woman receives during pregnancy, helps to ensure healthy outcomes for mother and newborns. Utilization of antenatal care services is the basic component of maternal care on which the life of mothers and babies depend.

Objectives : To find out the utilization of antenatal care services in a selected rural area in Bangladesh.

Methodology : Descriptive cross-sectional study was conducted between January to June 2014' A total 199 married women of reproductive age who had a live baby below 5years of age, were selected purposively from village Islampur in Dhamrai Upzilla under Dhaka district. Data were collected by face to face interview using a pre-tested structured questionnaire.

Result : The study revealed that $94.97 \%$ utilized ANC services among them $44.72 \%$ visited for ANC more than 4 times, $20.10 \%$ for 4 times and $30.15 \%$ less than 4 times during pregnancy. Health care centre was within walking distance. Most of them were young women aged between $23-27$ years $(45.72 \%$ ) and 18.22 years (36.18\%). Majority $(33.16 \%)$ was educated up to secondary level but $83.42 \%$ were house wife. Economic status was lower economic group. Half of the respondents $(52 \%)$ took ANC on their own and permission of husband and $95.97 \%$ received special care from their family during pregnancy. For birth planning $86.83 \%$ planned health provider to conduct delivery and $71.36 \%$ wanted hospital delivery. Majority $(97.98 \%)$ took birth preparedness during pregnancy and $55 \%$ received antenatal care from qualified doctor. About $87 \%$ found them available on duty and good behavior was found by $70.90 \%$ respondents. Information about danger signs during pregnancy were received by $77.89 \%$ of the respondents.

Conclusion : Utilization of Antenatal care service was higher in the study area. Most of the mothers had idea about benefit of ANC. Mother's education, family support, behaviour, availability of health care service provider and distance of health centre influence higher utilization. Therefore, to strengthen and intensify the ANC service at all level of health care delivery throughout the country is necessary for sustainability and targeting suboptimum ANC utilization group.

Key words : Antenatal care, birth planning, birth preparedness, danger sign.

\section{Introduction}

Pregnancy is potentially risky for all women worldwide. Millions more women survive but suffer from illness and disability related to pregnancy and childbirth ${ }^{1}$ Antenatal care may assist in abating the severity of pregnancy related complications through monitoring and prompt treatment. The availability of routine prenatal (antenatal care) care has played a part in reducing maternal death rates, miscarriages, low birth weight and other preventable health problems. $^{2}$
Antenatal care (ANC) is a type of preventative care with the goal of providing regular check-ups that allow doctors or midwives to treat and prevent potential health problems throughout the course of the pregnancy while promoting healthy lifestyles that benefit both mother and child. During check-ups, women will receive medical information over maternal physiological changes in pregnancy, biological changes, and prenatal nutrition including prenatal vitamins. Recommendations on management and healthy lifestyle changes are also made during regular check-ups.

It also offers opportunity to inform women about the danger signs and symptoms which require prompt attention from a health care provider. Key components of ANC include the communication of health-related information, screening for risk factors, the prevention and management of complications, and planning for delivery in a safe place by skilled attendants, tetanus toxoid immunization, iron supplementation, preparation for transportation to a delivery site. The ultimate aim of ANC is to achieve healthy babies and healthy mothers at the end of pregnancy. ${ }^{3}$

The ANC service inevitably require necessary health infrastructure and health professionals with appropriate skills and experience particularly in poor countries where pregnant women are at increased risk of morbidity and mortality due to poverty, malnutrition and infections. ${ }^{4}$

The use of ANC in developing countries is low compared to developed countries (97\%). In developing countries, women spend more time on their multiple responsibilities for care of children, collecting water or fuel, cooking, cleaning, and trade than on their own health. They think it is a natural phenomenon and ignore in taking health care during pregnancy. $^{5}$

The World Health Organization (WHO) recommends four antenatal care visits for women whose pregnancies are progressing normally, with the first visit in the first trimester (ideally before 12 weeks but no later than 16 weeks), and at 24-28 weeks, 32 weeks and 36 weeks. Each visit should include care that is appropriate to the woman's overall condition and stage of pregnancy, and help her prepare for birth and care of the newborn. If problems or potential problems that will affect the pregnancy and newborn are detected, the frequency and scope of visits are increased. ${ }^{6}$

Comparable data from the 2004 and 2007 Bangladesh Demography and Health Statistic (BDHS) showed that 
while antenatal care from any provider had increased by 17 percent over the past few years (from 58 percent in 2004 to 68 percent in 2011), antenatal care from a medically trained provider during the same period had increased by 7 percent only (from 51 to 55 percent, respectively). ${ }^{7}$ Available information suggests that about 12,000 women in Bangladesh die due to pregnancy-related complications. The reduction of maternal mortality requires early detection of high risk pregnancies through appropriate antenatal care at community level and the existence of a mechanism to ensure timely access to referral facilities. $^{8}$

\section{Materials and methods}

This cross-sectional type of descriptive study was carried out between January to J une 2014. A total 199 married women of reproductive age who had one living child below five years were selected purposively from village Islampur in Dhamrai upazilla under Dhaka district. After taking informed consent, data were collected by face to face interview, using a pre-tested questionnaire. Data was entered into SPSS version 16.0 and analyzed by the researchers.

\section{Results}

Socio demographic profile of respondents revealed that utilization of ANC service was highest (45.72\%) among the age group 23-27 yrs. Education level was up to secondary $33.16 \%$ and primary level $28.64 \%$. Most of the respondents (83.42\%) were house wife. Monthly income was between 5001-10000Taka (34.67\%) families. (Table 1)

Table I : Socio demographic profile of respondents (no.199) Age of respondents

$\begin{array}{lcc}\text { Age Group } & \text { Frequency } & \text { Percentage } \\ \text { Below } 18 & 06 & 03.02 \% \\ 18-22 & 72 & 36.18 \% \\ 23-27 & 91 & 45.72 \% \\ 28-32 & 30 & 15.08 \%\end{array}$

Educational status of the respondents

$\begin{array}{lcc}\text { Educational Status } & \text { Frequency } & \text { Percentage } \\ \text { Illiterate } & 07 & 03.51 \% \\ \text { Can Sign } & 15 & 07.53 \% \\ \text { Primary Level } & 57 & 28.64 \% \\ \text { Secondary Level } & 66 & 33.16 \% \\ \text { S.S.C/Equivalent } & 31 & 15.58 \% \\ \text { Graduate/Above } & 23 & 11.58 \%\end{array}$

\section{Occupation of the respondents}

$\begin{array}{lcc}\text { Occupation } & \text { Frequency } & \text { Percentage } \\ \text { Housewife } & 166 & 83.42 \% \\ \text { Service } & 12 & 6.03 \% \\ \text { Housemaid } & 05 & 2.51 \% \\ \text { Garments Worker } & 13 & 06.53 \% \\ \text { Day Labourer \& others } & 03 & 01.51 \%\end{array}$

Monthly income of the family of the respondents

$\begin{array}{lcc}\text { Income (Tk) } & \text { Frequency } & \text { Percentage } \\ \text { Below 5,000 } & 27 & 13.57 \% \\ 5001-10,000 & 69 & 34.67 \% \\ 10001-15,000 & 47 & 23.62 \% \\ 15001-20,000 & 24 & 12.06 \% \\ \text { Above } 20,000 & 32 & 16.08 \%\end{array}$

\section{Socio cultural Factors}

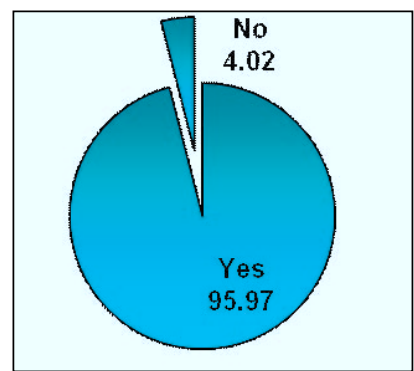

Fig 1 Special care of pregnant mother from family

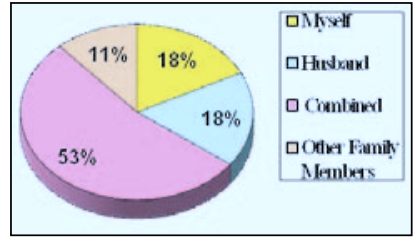

Fig 2 Permission for Antenatal Check up

Results on socio cultural factors showed $95.97 \%$ of respondents received special care from their family during pregnancy where as $4.03 \%$ respondents did not. (Fig 1) For ANC husband gave permission for $18 \%$ and $18 \%$ on own will. Combined wish was $53 \%$ and $12 \%$ after permission of other family members (Fig 2). Information about ANC service $45 \%$ received from family. Only $13 \%$ got information from mass media. (Fig 3). Idea about importance of utilizing antenatal care service showed that $41 \%$ mothers thought ANC important for safe delivery. About $23 \%$ thought for having a healthy mother, 34\% thought for a healthy baby and 2\% don't know about its importance. (Table II)

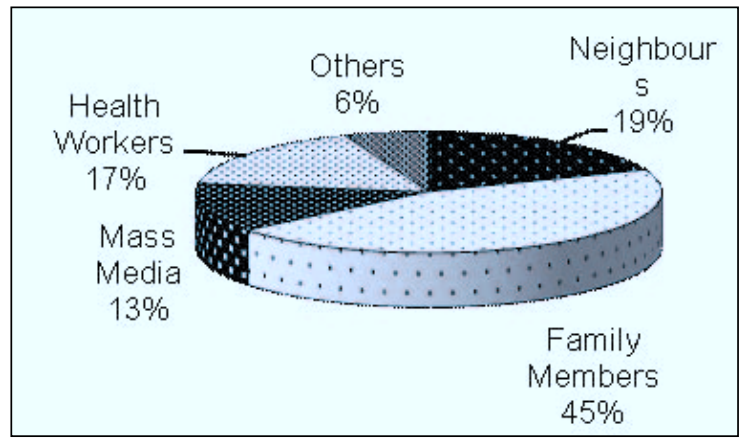

Fig 3 Source of information

Table II I dea about importance of utilizing antenatal care service

Variable Frequency Percentage

Safe Delivery

120

$40.82 \%$

Healthy Mother

67

$22.79 \%$

Healthy Baby

100

$34.01 \%$

Don't Know

7

$02.38 \%$

Total

294

$100 \%$

* Multiple Responses 


\section{Birth planning of respondents}

Table III Person will conduct delivery (no. 199)

$\begin{array}{lcc}\text { Person } & \text { Frequency } & \text { Percentage } \\ \text { Dai } & 20 & 10.05 \% \\ \text { Trained Birth Attendant } & 40 & 20.10 \% \\ \text { Doctor } & 133 & 66.83 \% \\ \text { Family Member } & 06 & 03.02 \%\end{array}$

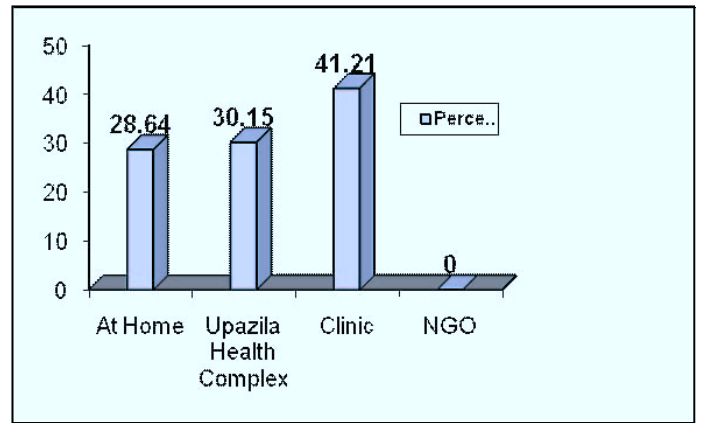

Fig 4 Choice for place of child birth

Table IV : Preparedness for delivery during pregnancy (no. 199)

$\begin{array}{lcc}\text { Preparation for delivery } & \text { Frequency } & \text { Percentage } \\ \text { Yes } & 195 & 97.98 \% \\ \text { No } & 04 & 02.02 \%\end{array}$

Birth planning of respondent's showed that $66.83 \%$ respondents planned that doctor to conduct the delivery, $20.1 \%$ by trained birth attendants, $10.5 \%$ by dais and $3.01 \%$ by family members. (Table V). Regarding place of child birth $28.64 \%$ respondents want to give birth of their child at home, $30.1 \%$ at upazila health complex, $41.2 \%$ at clinic and none at NGO. (Fig 4) and 97.98\% respondents took birth preparedness during pregnancy where as $2.02 \%$ did not. (Table IV).

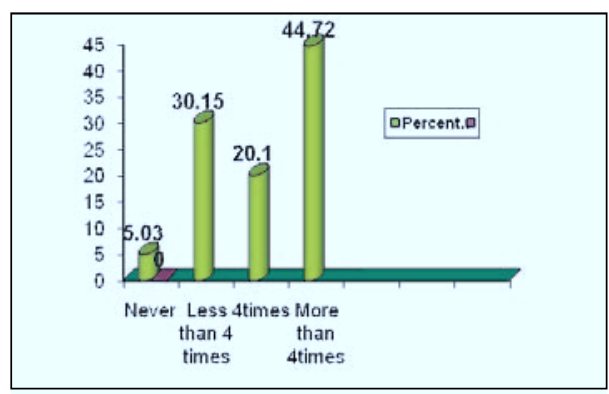

Fig 5 : Number of ANC service taken in the last pregnancy (No-199)

Table V : Antenatal Care Service related factor

Antenatal care service provider (No-189)

$\begin{array}{lcc}\text { ANC Service Provider } & \text { Frequency } & \text { Percentage } \\ \text { Health Assistant } & 16 & 8.47 \% \\ \text { Paramedic } & 02 & 1.06 \% \\ \text { Nurse } & 19 & 10.05 \% \\ \text { Doctor } & 104 & 55.03 \% \\ \text { Specialized Doctor } & 48 & 25.39 \%\end{array}$

Availability of the health care provider (No-189)

$\begin{array}{lcc}\text { Available } & \text { Frequency } & \text { Percentage } \\ \text { Yes } & 165 & 87.31 \% \\ \text { No } & 24 & 12.69 \% \\ \text { Behavior of the health care provider (No-189) } & \\ \text { Behavior } & \text { Frequency } & \text { Percentage } \\ \text { Very Good } & 54 & 28.57 \% \\ \text { Good } & 134 & 70.90 \% \\ \text { Bad } & 01 & 0.53 \%\end{array}$

Information given about danger signs during pregnancy (No-189)

$\begin{array}{lcc}\text { Information Given } & \text { Frequency } & \text { Percentage } \\ \text { Yes } & 150 & 79.37 \% \\ \text { No } & 39 & 20.63 \%\end{array}$

Distance of health care centre from the residence of respondents (No-189)

$\begin{array}{lcc}\text { Distance } & \text { Frequency } & \text { Percentage } \\ \text { Within walking distance } & 88 & 46.56 \% \\ \text { Needed transport } & 101 & 53.44 \% \\ \text { Vaccination during pregnancy } & (\text { No-189) } & \\ \text { Vaccinated } & \text { Frequency } & \text { Percentage } \\ \text { Yes } & 135 & 71.43 \% \\ \text { No } & 54 & 28.57 \%\end{array}$

Among the respondents 5.02\% never took ANC service, 30.15\% took ANC for less than 4 times, $20.1 \%$ took 4 times and $44.72 \%$ took ANC for more than 4 times during pregnancy. (fig V) Those attended for ANC service $8.47 \%$ respondents' service was provided by health assistant, $1.06 \%$ by paramedic, $10.05 \%$ by nurse, $55.03 \%$ by doctor and $25.39 \%$ by specialized doctor. Service provider was available $87.31 \%$ and good behavior was observed by $70.90 \%$ respondents. Information about danger signs during pregnancy were given to $77.89 \%$ of the respondents. Health care centre was within walking distance $46.56 \%$ respondents. Regarding vaccination status during pregnancy $71.43 \%$ of the respondents were vaccinated. (Table V)

\section{Discussion}

The study revealed that quite a significant proportion of the study participants were young aged women between 23-27years $(45.72 \%)$ and $18-22$ years (36.18\%), here younger women seek ANC more than older women. Similar result was found in a study in rural Nepal that the majority of the women attended for Antenatal care were younger age of $20-24$ years. ${ }^{9}$ Most of the mothers $83.42 \%$ were house wife and educated up to Secondary level (33.16\%) and primary level $(28.64 \%)$. Md. Mosiur Rahman et al carried out a study in Bangladesh found educated women were more likely to attend for ANC during pregnancy than less educated and illiterate women. Educated women can realize the benefits of using maternal healthcare services. Education increases female autonomy, decision-making power within the household and capability to make decisions regarding their own health. ${ }^{7}$

Socio economic status among the respondents revealed that lower income groups (48.24\%) had attended for ANC. In a study in rural India revealed similar result that most of the women attended for Antenatal care were from lower economic class ${ }^{10}$. Opposite picture was found by N. Nisar and F. White that women of higher income were two times more likely to use antenatal care services as compared to the lower income group (OR=2.11,95\% Cl 1.14-3.89) in urban settlement of Pakistan. ${ }^{11}$

Socio cultural aspects revealed that among the respondents $95.97 \%$ received special care from their family during pregnancy. Special care during pregnancy includes increase the amount of food, introducing protein (fish, meat), vegetables, milk and iron and vitamin supplementation. The current study revealed that about $52 \%$ respondents took ANC both with her own concern and permission of 
husband. A study in Indonesia found that pregnant women took their family permission without question because they trusted them and they wanted their family to be happy with them. ${ }^{12}$ Regarding source of information only negligible number $13 \%$ had media exposure. The result was not consistent with a study in Pakistan where media exposure was the main source of information. ${ }^{11}$ Appropriate knowledge and attitude is vital in ensuring sustainable acceptance of antenatal services. In our study $98 \%$ women had good idea on importance of utilizing ANC service $41 \%$ mothers thought ANC important for safe delivery.

In birth planning significant number of women planned health providers to conduct delivery as they thought that delivery conducted by health professional was better than dai (traditional birth attendant) which was reflected in the result that $66.83 \%$ respondents chose doctors, $20.1 \%$ chose trained birth attendants. Only $10.5 \%$ and $3.01 \%$ chose dais and family members to conduct the delivery. Again it was also observed that only $28.64 \%$ of respondents wanted home delivery and rest $71.36 \%$ preferred hospital delivery.

Regarding birth preparedness 97.98\% mothers were alert and conscious in saving money, arranging transport and made everything ready for any emergency during pregnancy. In Sub-Saharan Africa study results particularly establish that receipt of advice not only increases the likelihood of institutional delivery but it also heightens the effects of antenatal care on institutional delivery. ${ }^{13}$

It was evident from our study result that $5.02 \%$ respondents never took ANC care, and $94.97 \%$ utilized ANC service. Among them $30.15 \%$ took ANC for less than 4 times, $20.1 \%$ took 4 times and $44.72 \%$ took ANC for more than 4 times during pregnancy. Women of our study were educated, conscious about their health and utilized antenatal care service during pregnancy. This result is consistent with the study done in rural Nepal. ${ }^{9}$ Another study in Bangladesh found that $55 \%$ received two antenatal visits, $33 \%$ received three to four visits, and $12 \%$ received five or more than five visits. ${ }^{8}$

Regarding antenatal care service provider majority $55.03 \%$ from doctor and $25.39 \%$ from specialized doctor. Similar picture was found in a study conducted in a rural area at province of Sindh in Pakistan according to their results most of their respondents had ANC from doctor. ${ }^{14}$

On asking availability of health care provider participants answered that health care provider was available for $87 \%$ respondents. Opposite scenario was found in a study in southern Nigeria that only $27.4 \%$ staffs were always present. ${ }^{15}$

In the recent study regarding the behavior of health care provider $28.57 \%$ of respondents got very good behavior, $70.90 \%$ of respondents got good behavior and $0.53 \%$ got bad behavior from the health care provider. Opposite picture was found in Zmbabwe by Mathole et al. explained that poor attitude of health care providers towards pregnant women contributes to low utilization of ANC services in Zimbabwe ${ }^{16}$ Regarding advice on danger sign during pregnancy $79.37 \%$ of the respondents answer was positive that got information about danger signs during pregnancy where as $20.63 \%$ were not informed. Sulochana Dhakal et al showed in a study in Nepal that $79 \%$ women received health advice during their ANC. Most women received suggestions for a nutritious diet (84\%), while only $27 \%$ got advice on danger signs in pregnancy. ${ }^{9}$

Pregnant women may find it difficult to travel long distance for taking antenatal care in rural areas especially when the condition of the roads is poor. In our study among those who attended ANC, $46.56 \%$ respondents said health care centre within walking distance and $53.44 \%$ respondents had to go there by vehicle. This can be explained that rural women were conscious and knew the benefit of ANC and they reached health centre by foot or by vehicle. The result of this study is consistent with the study in the rural Guatemala. ${ }^{17}$

In our study it was observed that $71.43 \%$ of the respondents were vaccinated against Tetanus and $28.57 \%$ were not vaccinated during pregnancy. Similarly another study in Bangladesh revealed that $73 \%$ received Tetanus toxoid vaccine (TT) during their ANC visit. ${ }^{18}$

\section{Conclusion}

Utilization of antenatal care service was satisfactory $(94.97 \%)$ in our study area which is higher than national figure (68\%). Rural women of study area were found educated had knowledge on benefit of Antenatal care though they are from lower economic group but very enthusiastic in utilization of ANC service. Availability and accessibility of high quality ANC services, promoting information, education and communication in the community is recommended to increase effective and sustain utilization of ANC service.

\section{References}

1. Zeine Abosse, Mirkuzie Woldie and Shimeles Ololo; Factors Influencing Antenatal CareServiceUtilization inHadiya Zone: Ethiop J Health Sci. Jul 2010; 20(2): 75-82.

2. Antenatal Care- Wikipedia, the free encyclopedia en.wikipedia.org/wiki/antenatal care contraception

3. Abou Zahr C: Safe motherhood: a brief history of the global movement 1947-2002. Br Med Bull 2003, 67:13-25

4. Shahjahan et al. Antenatal care services in rural Bangladesh; South East Asia Journal of Public Health 2012; 2(2):61-66

5. Niguse M, Hailemariam D, Mitike G. Assessement of safe delivery service utilization among women of childbearing age in north Gondor Zone, North West Ethiopia; Ethiop J Health Dev. 2004; 18(3): 145-152

6. Villar J and Bergsjo P. 2003. WHO Antenatal Care Randomized Trial: Manual for the Implementation of the New Model. WHO/RHR/01.30. WHO: Geneva

7. M.H. Rahman, W.H. Mosley, S. Ahmed, H.H. Akhter, Does service accessibility reduce socioeconomic differentials in maternity care seeking? evidence from rural Bangladesh, J ournal of Biosocial Science, 40(1), (2008), 19-3310, 11

8. Anwar I, Kalim N, Koblinsky M. Quality of obstetric care in public-sector facilities and constraints to implementing emergency obstetric care services: evidence from high and low-performing districts of Bangladesh.J Health Popul Nutr2009;27:139-55.

9. Sulochana Dhakal, Edwin R van Teijlingen, Jane Stephens, Keshar Bahadur Dhakal, Padam Simkhada, Edwin Amalraj Raja, N. Glyn Chapman; ANTENATAL CARE AMONG WOMEN IN RURAL NEPAL: A COMMUNITYBASED STUDY; Online Journal of Rural Nursing and Health Care, vol. 11, no. 2, Fall 2011: 77-87.

10. Anna M V E, Hanneke M B, Frank O, J ohn G A, Ilse E B, Daniel H R, Kubaje A, Laurence $S$ and Kim A L; Use of antenatal services and delivery care among women in rural western Kenya: a community based survey; reproductive health journal: BioMed Central Ltd; 06 April 2006, p 3-5.

11. N. Nisar, E White Factors affecting utilization of Antenatal Care among reproductive age group Women (15-49 years) in an urban squatter settlement of Karachi: JPMA, January 2008; 62:148-52.

12. Wulandari LPL, Whelan KA: Beliefs, attitudes and behavior of pregnant women in Bali. Midwifery 2010, doi:10.1016/j.midw.2010.09.005.

13. Béatrice Nikiémal, Gervais Beninguisse and Jeannie L Haggerty; Providing information on pregnancy complications during antenatal visits: unmet educational needs in subSaharan Africa; Oxford J ournals Medicine Health Policy and Planning, 2009: Volume 24, Issue 5, Pp. 367-376.

14. Council P: Improving Maternal and Neonatal Health, Measuring the impact of the PIMAN Project in Ten Districts in Pakistan, In. Islamabad, 2010

15. Nwosu BO, Ugboaja JO, Obi-Nwosu AL, Nnebue CC, Ifeadike CO; Proximate determinants of antenatal care utilization among women in southeastern Nigeria: Niger J Med. 2012 Apr-Jun;21(2):196-204

16. Mathole T, G, Majoko F, Ahlberg BM. A qualitative study of women's perspectives of antenatal care in a rural area of Zimbabwe. Midwifery, 2004; 20(2), 122-132

17. D.A. Glei, N. Goldman, G. Rodriguez, Utilization of care during pregnancy in Rural Guatemala: does obstetrical need matter?, Social Science and Medicine, 57(12); (2003): 2447-2463.

18. Rahman M, Islam R, Rahman M.Antenatal care seeking behavior among slum mothers. A Study of Rajshahi CityCorporation Bangladesh;SQU Med J 2010;10:50-6. 